\title{
LA FUNCIONALIDAD DEL ARTÍCULO 99 \\ DE LA CONSTITUCIÓN ANTE EL CASO DE UN \\ RESULTADO ELECTORAL FRAGMENTADO: ¿MEJORAR \\ SU APLICACIÓN O PROPONER SU REFORMA?
}

The Functionality of Article 99 of the Constitution in the Case of a Fragmented Electoral Outcomes:

To Improve its Application or to Propose its Reform?

\author{
MIGUEL REVENGA SÁNCHEZ \\ Universidad de Cádiz \\ miguel.revenga@uca.es
}

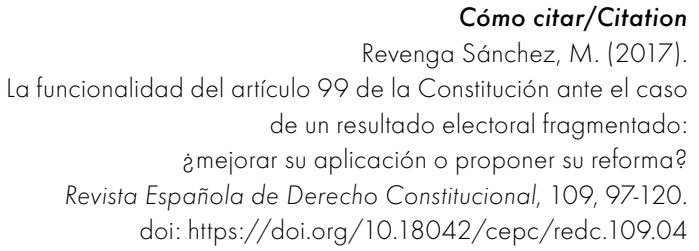

Resumen

El presente trabajo examina el largo proceso de formación de Gobierno que hemos tenido en España a lo largo de los últimos meses. El artículo explica los cambios en la situación política y evalúa el funcionamiento del art. 99 de la Constitución a la luz de estos. Una especial consideración se presta al papel del rey en el procedimiento de formación del Gobierno, en términos generales y prestando atención a la actuación del rey Felipe VI. El artículo termina planteando si conviene o no reformar el artículo estudiado y concluye proponiendo algunos retoques de la legislación ordinaria que mejoren su aplicación en el futuro.

\section{Palabras clave}

Procedimiento de formación del Gobierno; papel del rey; voto de investidura presidencial; reformas del procedimiento. 


\section{Abstract}

This paper examines the long process of government formation that we had in Spain over the last few months. The paper explains the changes in the political situation and evaluates the functioning of article 99 of the Constitution. Special consideration is given to the role of the king in the procedure of formation of the Government, in general terms, and paying special attention to the performance of King Philip VI. The paper concludes asking whether or not to reform the article studied, and concludes proposing some adjustments of the ordinary legislation that will improve its application in the future.

\section{Keywords}

Constitutional process of formation of Government; role of the King; parliamentary vote; legal reforms of the process. 
I. DEL PARLAMENTARISMO ESTABILIZADO AL PARLAMENTARISMO AGITADO: EL PAISAJE DE LA BATALLA. II. EL FACTOR TIEMPO, EL PAPEL DEL REY Y EL DE LA PRESIDENCIA DEL CONGRESO. III. LA INTERVENCIÓN DEL CONGRESO. IV. CONCLUSIÓN: ¿̇EL ARTÍCULO 99 DE LA CONSTITUCIÓN ESTÁ BIEN COMO ESTÁ O CONVENDRÍA REFORMARLO? BIBLIOGRAFÍA.

\section{DEL PARLAMENTARISMO ESTABILIZADO AL PARLAMENTARISMO AGITADO: EL PAISAJE DE LA BATALLA}

La permanencia de un Gobierno en funciones por espacio de tiempo superior a los diez meses y la repetición de elecciones como consecuencia de la disolución automática de las Cortes prevista en el art. 99 de la Constitución española (CE) han alterado profundamente la percepción que teníamos hasta ahora del funcionamiento de nuestro sistema parlamentario. Hasta la convocatoria de diciembre de 2015, los resultados electorales habían dirimido siempre la cuestión de quién debía gobernar como consecuencia de ellos. Y en esas condiciones la aplicación del procedimiento de formación de Gobierno regulado en los arts. 99 y 100 de la CE fue siempre percibido como la sustanciación ritual de unos trámites por cuyo conducto se culminaba de manera natural la operación de recambio del Gobierno cesante por un nuevo Gobierno en plenitud de atribuciones y respaldado por una mayoría del Congreso suficiente para gobernar.

Cuando hace ya bastantes más años de los que uno quisiera publiqué una versión mutilada de mi tesis doctoral sobre la formación del Gobierno en la $\mathrm{CE}$, comenzaba justificando el trabajo con unas consideraciones en las que explicaba que el momento de la instauración del nexo fiduciario entre el Gobierno y el Parlamento - y no las situaciones patológicas de quiebra del mismo en el transcurso de la legislatura - era el factor clave para entender el significado del régimen parlamentario y para buscar indicaciones precisas acerca de su funcionamiento efectivo ${ }^{1}$. Con el apoyo del usual aparato de citas propio de quien inicia una andadura académica, llamaba también la atención sobre el interés de un momento institucional singularmente propicio para captar la tensión entre norma constitucional y realidad política, así como para evaluar el modo en el que la pluralidad de sujetos que lo protagonizan (cuerpo

1 Revenga Sánchez (1988: 11-12). 
electoral, fuerzas políticas, jefatura del Estado y Congreso de los Diputados con su presidente) son capaces o no de actuar de consuno para culminar con éxito la operación de recambio. Por supuesto que hablar del cuerpo electoral como un sujeto constitucional capaz de expresarse es más una licencia que otra cosa. Pues siendo la voluntad del electorado no una sola, sino una voluntad plural y, por ello mismo, sujeta a múltiples interpretaciones, lo más que puede decirse de ella a nuestros efectos es que tal voluntad es el factum político del que se parte para iniciar el proceso, y ello solo una vez que las normas electorales han procedido a depurarla para convertirla en un reparto de los escaños del Congreso de los Diputados, que es la aritmética - mayoría absoluta o mayoría simple- que tiene presente el art. 99 de la CE. Dicho lo cual, me apresuro a añadir que, en la línea que vincula la voluntad del electorado con la formación de un Gobierno, no hay en el régimen parlamentario más que dos opciones: en la primera, tal voluntad indica más allá de cualquier duda quién debe gobernar; en la segunda no lo hace, por lo que los resultados electorales y el reparto de escaños condicionan, pero no determinan, mecánicamente el signo político del Gobierno. Son, como se dice a veces acudiendo a una imagen llena de plasticidad, las cartas que han correspondido a cada fuerza en el reparto, y con las que se inicia un juego que se rige por reglas que todos aceptan, pero en el que el desenlace es esencialmente abierto e indeterminado.

Desde la aprobación de la CE en 1978, los españoles hemos sido llamados para elegir a los miembros de las dos Cámaras de las Cortes Generales en un total de doce ocasiones. Para hacerse una idea de las transformaciones en el paisaje político que se han producido en las dos últimas de tales convocatorias (las de diciembre de 2015 y junio de 2016) baste con pensar que en las diez que les precedieron el porcentaje de escaños logrado por los dos partidos más votados en el Congreso de los Diputados osciló entre un mínimo del $65,24 \%$ (en 1979) y un máximo del $83,81 \%$ en 2008 . Unos porcentajes tan elevados de escaños sobre los 350 que tiene el Congreso son un buen indicio de la acusada impronta bipartidista que ha tenido hasta 2015 el sistema de partidos en España.

El hecho de que la competición partidista por la presidencia del Gobierno haya permitido hablar hasta las elecciones de 2015 de un partido que vence al otro en el escenario nacional y se hace, por tanto, acreedor a que aquel que encabeza la lista por la circunscripción de Madrid sea presentado ante los electores (y tenido por estos) como el candidato natural a presidir el Gobierno previa obtención de la confianza parlamentaria explica mejor que ninguna otra consideración cómo se ha materializado tradicionalmente el proceso de formación de Gobierno en España. Una plasmación práctica que siempre permitió anudar, en 
un tracto perfectamente pautado, los resultados electorales, la intervención del rey en la propuesta de candidato a presidente del Gobierno a la vista de la correlación de fuerzas en el Congreso el debate sobre el programa del candidato y la votación de la investidura en un proceso de aplicación mecánica y ritual del diseño constitucional que ahora se ha trastocado por completo.

En la España de la CE de 1978, solo hemos conocido Gobiernos homogéneos. Gobiernos en los que la derecha moderada (encarnada primero en UCD y sucesivamente en AP y PP) y la izquierda moderada (encarnada en el PSOE) se han ido sucediendo en la presidencia del Gobierno gracias a un comportamiento de los electores que ha dado lugar a ciclos o períodos de alternancia bien diferenciados. En conjunto, durante las diez primeras legislaturas se formaron en España once Gobiernos homogéneos ${ }^{2}$. De ellos, cinco (los formados por el PSOE en 1982, 1986, 1989 y los formados por el PP en 2000 y en 2011) dispusieron de mayoría absoluta por llegar o superar, en apoyo parlamentario, a la mitad de los miembros de derecho del Congreso. Y seis fueron Gobiernos homogéneos de tipo minoritario: los formados por la UCD en 1979 y 1981, por el PSOE en 1993, 2004 y 2008, y por el PP en 1996. De estos últimos, todos menos el formado por el PP en 1996 dispusieron de un apoyo parlamentario superior al $45 \%$ de los escaños (157 sobre 350). En ese supuesto estuvieron los Gobiernos de UCD en 1979 y 1981 (168 escaños) y los del PSOE en 1993 (159 escaños), 2004 (164 escaños) y 2008 (169 escaños). Y en todos y en cada uno de los casos, la dificultad de afrontar la legislatura en defecto de mayoría absoluta fue exitosamente compensada mediante apoyos puntuales o pactos de legislatura acordados generalmente con las fuerzas políticas de carácter nacionalista (PNV, CiU y/o CC) que permitieron llevar la duración de los Gobiernos hasta un lapso temporal que superó siempre los tres años, con las solas excepciones de los Gobiernos formados por UCD en 1979 y 1981, en los inicios de la andadura constitucional, y el del formado por el PSOE tras las elecciones de junio de 1993, que apenas superó los treinta y tres meses ${ }^{3}$.

2 La pequeña discordancia entre el número de legislaturas (diez) y el de Gobiernos formados (once) se debe al hecho de que, en la primera de ellas, la UCD formó dos Gobiernos con distintas presidencias: el presidido por Adolfo Suárez (marzo de 1979-enero de 1981) y el presidido por Leopoldo Calvo-Sotelo (febrero de 1981 a octubre de 1982).

3 Sobre la experiencia española en la formación de Gobiernos minoritarios —en realidad, Gobiernos formales más que sustancialmente minoritarios-, véase Reniú Villamala (2002), así como, recientemente, Bonnie N. Field (2016). Agradezco al profesor José Ramón Montero el haberme facilitado esta última referencia. 
Con un paisaje de fondo como el someramente descrito, se comprende mejor la convulsión que se ha producido en España como consecuencia de los resultados electorales en las dos convocatorias sucesivas de diciembre de 2015 y junio de 2016. La fragmentación de acusada impronta bipartidista que caracterizó la composición del Congreso a lo largo de toda la etapa democrática dejó paso a una mucho más compleja tras las elecciones de diciembre de 2015. Para empezar, la suma del porcentaje de voto de los dos partidos, PSOE y PP, sobre quienes había recaído tradicionalmente la responsabilidad de formar Gobierno, apenas superó ahora el umbral del $50 \%$. Ello se tradujo, por efecto de los correctivos antiproporcionales de nuestro sistema electoral, en un porcentaje de escaños que, pese a subir hasta el 60,85\%, considerando los logrados por ambos partidos, es de lejos el más bajo de todos los que se han producido entre 1979 y 2016. El PP tuvo una espectacular bajada en votos y en escaños: perdió más de 3,6 millones de votos y bajó desde 186 a 123 escaños (63 escaños menos). El PSOE también fue abandonado por un número de electores algo superior a los 1,4 millones y bajó desde los 110 escaños de 2011 a los 90 que obtuvo ahora (veinte menos). La gran novedad en la composición del Congreso es la irrupción espectacular de las dos fuerzas políticas que han cambiado por completo las características de nuestro sistema de partidos. Las candidaturas de Podemos y lo que ha dado en llamarse sus confluencias lograron 69 escaños. Y las presentadas por el partido Ciudadanos alcanzaron los 40 escaños, de manera que la suma de escaños de las cuatro fuerzas principales llegó hasta los 312 sobre los 350 de que consta el Congreso (CUADro 1).

Los resultados electorales de 2015 reflejan por sí solos la necesidad ineludible de alcanzar pactos para conseguir superar el umbral mínimo de apoyo requerido por la $\mathrm{CE}$, pero no permiten comprender las razones por las cuales ninguna de las teóricas coaliciones posibles de fuerzas pudo llegar a materializarse con perspectivas favorables de éxito. A lo largo de los meses transcurridos desde diciembre de 2015 hasta octubre de 2016, hemos podido comprobar lo difícil que resulta acompasar las pautas de comportamiento de los partidos a escenarios políticos complejos y en los que, en defecto de la suficiente disposición a pactar, la dinámica de las disposiciones constitucionales actúa como un poderoso factor condicionante o compulsivo, pero no suple, ni puede ofrecer alternativa satisfactoria, la incapacidad de aquellos para comprometerse a superar la situación de bloqueo. 
CuAdro 1. Comparación de resultados de las elecciones al Congreso en 2011 y 2015

\begin{tabular}{|c|c|c|c|c|c|}
\hline $\begin{array}{c}\text { Candidaturas } \\
2015\end{array}$ & $\begin{array}{l}\text { Votos } 2015 \\
\text { (\%) }\end{array}$ & $\begin{array}{c}\text { Escaños } \\
2015(\%)\end{array}$ & $\begin{array}{c}\text { Candidaturas } \\
2011\end{array}$ & $\begin{array}{l}\text { Votos } 2011 \\
(\%)\end{array}$ & $\begin{array}{c}\text { Escaños } \\
2011(\%)\end{array}$ \\
\hline $\mathrm{PP}$ & $\begin{array}{c}7.215 .752 \\
(28,72)\end{array}$ & $\begin{array}{c}123 \\
(35,14)\end{array}$ & PP & $\begin{array}{c}10.866 .566 \\
(44,63)\end{array}$ & $\begin{array}{c}186 \\
(53,14)\end{array}$ \\
\hline PSOE & $\begin{array}{c}5.530 .779 \\
(22,01)\end{array}$ & $\begin{array}{c}90 \\
(25,71)\end{array}$ & PSOE & $\begin{array}{c}7.003 .511 \\
(28,76)\end{array}$ & $\begin{array}{c}110 \\
(31,42)\end{array}$ \\
\hline PODEMOS & $\begin{array}{c}5.189 .463 \\
(20,66)\end{array}$ & $\begin{array}{c}69 \\
(19,71)\end{array}$ & & & \\
\hline CIUDADANOS & $\begin{array}{c}3.500 .541 \\
(13,93)\end{array}$ & $\begin{array}{c}40 \\
(11,42)\end{array}$ & & & \\
\hline ERC-CATSI & $\begin{array}{c}599.289 \\
(2,39)\end{array}$ & $\begin{array}{c}9 \\
(2,57)\end{array}$ & ERC & $\begin{array}{c}256.985 \\
(1,06)\end{array}$ & $\begin{array}{c}3 \\
(0,85)\end{array}$ \\
\hline DLP & $\begin{array}{c}565.501 \\
(2,25)\end{array}$ & $\begin{array}{c}8 \\
(2,28)\end{array}$ & $\mathrm{CiU}$ & $\begin{array}{l}1.014 .263 \\
(4,17)\end{array}$ & $\begin{array}{c}16 \\
(4,57)\end{array}$ \\
\hline PNV & $\begin{array}{c}301.585 \\
(1,20)\end{array}$ & $\begin{array}{c}6 \\
(1,71)\end{array}$ & PNV & 324.317 & $\begin{array}{c}5 \\
(1,42)\end{array}$ \\
\hline IU-UPEC & $\begin{array}{c}923.133 \\
(3,67)\end{array}$ & $\begin{array}{c}2 \\
(0,57)\end{array}$ & IU-LV & $\begin{array}{c}1.686 .040 \\
(6,92)\end{array}$ & $\begin{array}{c}11 \\
(3,14)\end{array}$ \\
\hline OTROS & $\begin{array}{c}310.217 \\
(1,20)\end{array}$ & $\begin{array}{c}3 \\
(0,85)\end{array}$ & OTROS & $\begin{array}{c}2.064 .433 \\
(8,48)\end{array}$ & $\begin{array}{c}19 \\
(5,42)\end{array}$ \\
\hline
\end{tabular}

Fuente: elaboración propia.

En este sentido, la composición del Congreso resultante de las elecciones de 2016 confirma, a nuestro juicio, la idea de que la repetición de elecciones como consecuencia de la disolución automática subsiguiente a un procedimiento fallido de investidura no es fácil que arroje vuelcos espectaculares en el comportamiento de los electores (CUADro 2). Claro que un pronóstico como ese está condicionado por factores tan variables (tiempo transcurrido entre una y otra convocatoria, comportamiento de los partidos durante el frustrado proceso de formación de Gobierno y persistencia o cambio en los liderazgos de estos, por señalar algunos), y carece de casos de estudio tan escasos, que quizá no pasa de ser la exteriorización del puro rechazo frente a la incapacidad de los partidos para gestionar situaciones en las que la pluralidad de fórmulas posibles de gobierno no es sino la consecuencia de una voluntad de los electores que exige, para no resultar truncada, disposición leal a llegar a acuerdos. 
Cuadro 2. Comparación de resultados de las elecciones al Congreso en 2016 y 2015

\begin{tabular}{lccccc}
\hline \multicolumn{1}{c}{$\begin{array}{c}\text { Candidaturas } \\
\text { 2016 }\end{array}$} & $\begin{array}{c}\text { Votos 2016 } \\
(\%)\end{array}$ & $\begin{array}{c}\text { Escaños } \\
2016(\%)\end{array}$ & $\begin{array}{c}\text { Candidaturas 2015 } \\
(\%)\end{array}$ & $\begin{array}{c}\text { Votos 2016 } \\
(\%)\end{array}$ & $\begin{array}{c}\text { Escaños } \\
\text { 2016(\%) }\end{array}$ \\
\hline PP & 7.906 .185 & 137 & PP & 7.215 .752 & 123 \\
PSOE & $(33,03)$ & $(35,14)$ & & $(28,72)$ & $(35,14)$ \\
& 5.424 .709 & 85 & PSOE & 5.530 .779 & 90 \\
PODEMOS/IU & 5.049 .734 & 71 & PODEMOS & 5.189 .463 & 69 \\
& $(21,10)$ & $(20,28)$ & & $(20,66)$ & $(19,71)$ \\
CIUDADANOS & 3.123 .769 & 32 & CIUDADANOS & 3.500 .541 & 40 \\
& $(13,05)$ & $(9,14)$ & & $(13,93)$ & $(11,42)$ \\
ERC & 629.294 & 9 & ERC & 599.289 & 9 \\
& $(2,63)$ & $(2,57)$ & & $(2,39)$ & $(2,57)$ \\
CDC & 481.839 & 8 & DLP & 565.501 & 8 \\
& $(2,01)$ & $(2,28)$ & & $(2,25)$ & $(2,28)$ \\
PNV & 286.215 & 5 & PNV & 301.585 & 6 \\
& $(1,20)$ & $(1,42)$ & & $(1,20)$ & $(1,71)$ \\
OTROS & 262.172 & 3 & OTROS & 310.217 & 3 \\
& $(1,10)$ & $(0,85)$ & & $(1,20)$ & $(0,85)$ \\
\hline
\end{tabular}

Fuente: elaboración propia.

\section{EL FACTOR TIEMPO, EL PAPEL DEL REY Y EL DE LA PRESIDENCIA DEL CONGRESO}

Sin lugar a dudas, una de las características más llamativas del régimen constitucional de la formación del Gobierno en España es la manera en la que aparecen diseñadas las fuentes normativas con el fin de establecer un calendario preciso de actuaciones que desemboque en la sustitución del Gobierno cesante por un Gobierno investido de la confianza del Congreso y en plenitud de atribuciones. El art. 99 de la CE, la Ley Orgánica del Régimen Electoral General (LOREG), así como el Reglamento del Congreso de los Diputados, contienen, en ese sentido, un conjunto coordinado de reglas que enmarcan en límites temporales concretos las operaciones políticas que hay que poner en marcha para lograr dicha sustitución. Eso sucede especialmente así cuando - como ha ocurrido siempre en España salvo en el supuesto desencadenado por la dimisión de Adolfo Suárez en 1981- el procedimiento de investidura se activa como consecuencia de la celebración de elecciones. Cuando se disuelven las Cámaras, de manera anticipada o por expiración del 
período de mandato de los diputados y de los senadores a los cuatro años de su elección, el propio decreto de disolución tiene que establecer la convocatoria a las urnas (art. 115.1 de la CE y art. 42 de la LOREG). Este último precepto dispone además (en concordancia con el art. 68.6 de la $\mathrm{CE}$ ) que las elecciones habrán de celebrarse precisamente «el día quincuagésimo cuarto posterior a la convocatoria». Y una vez celebradas las elecciones y renovadas las Cámaras, es la propia CE (así mismo en el art. 68.6) la que marca un plazo de veinticinco días para convocar el Congreso. Así pues, desde que las Cámaras son disueltas y hasta que se produce la sesión constitutiva de las que surgen de la contienda electoral, entramos en un período en el que las disposiciones legales, las que disciplinan el procedimiento electoral y las que marcan los plazos para la reunión de los candidatos electos, funcionan como un mecanismo de relojería que proporciona, sin duda, la certeza de un impulso del proceso político, en su manifestación democrática más básica, perfectamente pautado y ordenado.

Sobre esos presupuestos, el art. 99 de la CE se nos aparece también como una sucesión escalonada de reglas bastante claras en cuanto a los tiempos en los que deben ser aplicadas y en cuanto a las exigencias que contienen, pero unas reglas en las que, junto a zonas diáfanas de luz, también surgen zonas que se dejaron, quizá deliberadamente, veladas para encajar el papel del rey en el procedimiento y para hacer frente a las eventuales dificultades que pudieran derivarse de cara a la formación de Gobierno en un plazo razonable de tiempo. Lo que hay de velado en la intervención del rey afecta, desde luego, a la propia sustancia de su posición constitucional como jefe del Estado de una monarquía parlamentaria. Una posición que es un desafío para el estado del arte de la hermenéutica constitucional, habida cuenta de las funciones que expressis verbis le asigna la CE, en términos generales (art. 56.1), pero también en términos de desarrollo y especificación de un número de competencias que le corresponden y que enuncia el art. 62; entre ellas, la de «proponer el candidato a Presidente del Gobierno y, en su caso, nombrarlo, así como poner fin a sus funciones en los términos previstos en la Constitución».

Quizá lo que distingue la competencia del rey en punto a la propuesta de candidato de cualquier otra que podamos encontrar desarrollada en la CE es que en esa propuesta de candidato que disciplina el art. 99 de la CE hay una conexión especialmente intensa entre la función genérica (arbitrar y moderar el funcionamiento regular de las instituciones) y la competencia concreta, lo que ha dado pie a exégesis diversas y contrapuestas. Es verdad que la regla general del refrendo de los actos del rey por el presidente del Gobierno o por los ministros competentes cuenta en el art. 64 de la CE con un añadido ad hoc para este supuesto («La propuesta y el nombramiento del Presidente del 
Gobierno, y la disolución prevista en el art. 99, serán refrendados por el Presidente del Congreso»), pero ello no significa que el debate sobre el papel del rey carezca de sentido, sobre todo si estamos de acuerdo en admitir que la función última del refrendo, aun siendo unívoca en todos los casos - la traslación de responsabilidad desde el monarca hasta el sujeto que refrenda, en consonancia con la inviolabilidad de la persona del rey y su no sujeción a responsabilidad, tal y como lo dispone el art. 56.3 de la CE-, es compatible con refrendos a los que cabe atribuir una distinta naturaleza sustantiva, en función de cuál sea la medida en la que la voluntad de quien refrenda interviene o influye en el contenido del acto refrendado ${ }^{4}$. Por más que insistamos en que el refrendo supone siempre, al fin y a la postre, una rúbrica mediante la cual quien la estampa asume la responsabilidad, es difícil negar que la relación entre este último y aquel cuyas actuaciones se refrendan puede variar según cuál sean las facultades y el margen de maniobra de las que uno y otro disponen durante tales actuaciones determinantes de la formación del acto o, mejor dicho, de la disposición que las culmina y exterioriza con la rúbrica de ambos. Para poner las cosas más difíciles, el propio art. 99 de la CE da pie para establecer distingos, pues, mientras que para el caso de la disolución automática por el decurso del tiempo habla de que el rey disuelve y convoca elecciones "con el refrendo del Presidente del Congreso" (art. 99.5 de la CE), en el caso de la propuesta de candidato a presidente de Gobierno se limita a decir que el rey la realizará «a través del Presidente del Congreso».

Por supuesto que, más allá de las sutilezas y los matices que podamos encontrar a la hora de regular las intervenciones regias, la verdadera clave del asunto se encuentra, como decimos, en esa asignación genérica de unas funciones arbitrales y moderadoras cuyo tronco teórico bebe de distintas fuentes, ya sea la constantiana elaboración del Pouvoir Moderateur ${ }^{5}$ o el influyente distingo de Bagehot entre partes de la Constitución efficients y partes de la

4 Por todos, Torres Muro (1995) y, en términos más generales, González Trevijano (1998).

5 «Los tres poderes políticos, tales como los hemos conocido hasta de presente, a saber, el ejecutivo, el legislativo y el judicial [dice Constant] son tres resortes que deben cooperar, cada uno por su parte, al movimiento general; pero cuando estos sacados fuera de su lugar se mezclan entre sí, se chocan o se embarazan, es necesario buscar una fuerza que los ponga en su lugar. Esta fuerza no puede existir en ninguno de los tres resortes, porque serviría para destruir a los demás. Y así debe estar fuera y ser neutral en cierta manera, a fin de que su acción se aplique en todas las partes donde sea necesaria, y para que preserve y repare sin ser hostil», Benjamin Constant (1820). Véase a este propósito la brillante relectura de Eloy García (2014). 
Constitución dignified que es el presupuesto sobre el que descansa su celebérrima enumeración de los tres «derechos» del rey $^{6}$.

La cuestión es que estos grandes teorizadores del poder monárquico tenían ante sus ojos formas de monarquía que actuaban en escenarios políticos que no se caracterizaban precisamente por el compromiso radical con una atribución de la soberanía al pueblo. Mientras que, en el caso de nuestra CE de 1978, tal compromiso no es solo el punto de arranque de la operación constitucional en su conjunto, sino el leitmotiv de una calificación de la forma política del Estado, la de la monarquía parlamentaria, sobre cuya ortodoxia en términos dogmáticos se ha discutido mucho, pero en la que no cabe dudar del carácter inédito de una cualificación de la monarquía con connotaciones muy precisas. Dicho en breve: la monarquía parlamentaria de la CE de 1978 no deja en manos del titular de la corona fondo residual de poder político alguno que pueda activarse para colmar vacíos o remediar insuficiencias en la actuación de las fuerzas políticas, y ello tanto en condiciones de normalidad constitucional como en los supuestos que se adentren por los terrenos de lo excepcional. Tal y como nosotros la entendemos, la $\mathrm{CE}$ es en esto particularmente clara y no deja resquicio para interpretaciones que permitan un descenso ocasional del jefe del Estado a la arena de la política activa para decantar - o contribuir a que se decante- esta o aquella solución o fórmula de gobierno con preferencia a esta o aquella otra. Su posición como instancia supra partes es un contrapeso necesario — diría más: consustancial — a su condición de jefe del Estado de una monarquía parlamentaria; una monarquía, por cierto, en la que las Cortes Generales disponen siempre de la llave para decretar la imposibilidad de la permanencia en el cargo del titular de la corona cuando este «se inhabilitare para el ejercicio de su autoridad» (art. 59.2 de la CE).

Así las cosas, se nos aparece todavía más complicado —más velado decíamos antes- emplazar lo que, en consonancia con su posición constitucional, le corresponde hacer al rey durante el procedimiento de formación del Gobierno. Hasta el reciente y espectacular impasse de estos últimos meses, era

6 Permítaseme, respecto a esto último, reproducir la cita literal de lo que dice Bagehot en su libro sobre la Constitución inglesa cuya primera edición es de 1867: «To state the matter shortly, the sovereign has, under a constitutional monarchy such as ours, three rights: the right to be consulted, the right to encourage, the right to warn». Y añade: «And a king of great sense and sagacity would want no others. He would find that his having no others would enable him to use these with singular effect [...]», Walter Bagehot (1974).

7 Véase últimamente sobre esto y abogando por un cumplido desarrollo legislativo capaz de racionalizar hasta sus ultimas consecuencias los actos del rey, Enrique Belda (2015). 
bastante sencillo concluir que al rey no le compete nada distinto a la función de un activador mecánico de las distintas fases del proceso; es decir, recibir en consulta a los representantes de los grupos políticos, proponer candidato y nombrar presidente del Gobierno al confirmado por el Congreso, todo ello en coordinación y sintonía con el presidente de esta Cámara que es quien refrenda las dos últimas operaciones recién señaladas. Pero ahora, por vez primera en nuestra práctica constitucional y por vez primera, también, en la experiencia del rey Felipe VI tras la abdicación de su padre en 2014, se han dado circunstancias que hacen de obligado repaso y nueva consideración las exégesis constitucionales realizadas hasta el momento.

Una primera constatación: el largo proceso de gestación de Gobierno (CUADro 3), con dos investiduras fallidas (la del candidato del PSOE, Pedro Sánchez, en marzo de 2016 y la de Mariano Rajoy, en su primer intento, en septiembre de 2016) y dos elecciones generales de por medio, ha dado ocasión para que, por vez primera, haya una posición oficial de la corona transmitida a la opinión pública por medio de comunicados de la Casa del Rey. Pero antes de entrar en su contenido, quizá convenga recapitular someramente la secuencia de los acontecimientos.

CuAdro 3. Número de días invertidos en la realización de los trámites previstos en el artículo 99 de la CE para la investidura del presidente del Gobierno (1979-2016)

\begin{tabular}{lcc}
\hline \multicolumn{1}{c}{ Gobierno } & Fechalsupuesto desencadenante & Fecha de la investidura (número de días) \\
\hline Suárez II & Elecciones 01-03-1979 & 30-03-1979 (27) \\
Calvo Sotelo & Dimisión 29-01-1981 & 25-02-1981 (26) \\
González I & Elecciones 28-10-1982 & $01-12-1982(33)$ \\
González II & Elecciones 22-06-1986 & 23-07-1986 (29) \\
González III & Elecciones 29-10-1989 & $05-12-1989(36)$ \\
González IV & Elecciones 06-06-1993 & $09-07-1993(31)$ \\
Aznar I & Elecciones 03-03-1996 & $04-05-1996(60)$ \\
Aznar II & Elecciones 12-03-2000 & $26-04-2000(43)$ \\
Zapatero I & Elecciones 14-03-2004 & $16-04-2004(32)$ \\
Zapatero II & Elecciones 09-03-2008 & $10-04-2008(31)$ \\
Rajoy I & Elecciones 20-11-2011 & $20-12-2011(29)$ \\
Rajoy II & Elecciones 20-12-2011 & $29-10-2016(315)$ \\
& Elecciones 26-06-2016 & \\
\hline
\end{tabular}

Fuente: elaboración propia. 
Desde las elecciones generales de diciembre de 2015, y hasta la investidura de Rajoy en octubre de 2016, el rey celebró hasta cinco rondas de consultas con los representantes de las fuerzas políticas, como así lo dispone el art. 99.1 de la CE: tres tras las elecciones de 2015 y dos más tras las elecciones de 2016. Las dos primeras rondas de consultas se celebraron entre los días 18 a 22 de enero y 27 a 29 de enero, respectivamente. Desembocaron en la propuesta como candidato del líder del PSOE, Pedro Sánchez, que fracasó en su intento de obtener la confianza del Congreso el 4 de marzo (CUADRo 4). La tercera ronda de consultas se celebró los días 25 y 26 de abril. Sirvió para constatar la falta de acuerdo entre los partidos y precedió en pocos días a la disolución automática de las Cortes (mediante Real Decreto de 3 de mayo) que el rey expidió al día siguiente de que expirara el plazo de los dos meses a partir de la primera votación de investidura establecido en el art. 99.5 de la CE. Tras las elecciones de 26 de junio, el rey celebró una nueva ronda de consultas entre el 26 y el 28 de julio, que culminó ese mismo día en la propuesta de Mariano Rajoy como candidato a la presidencia. Una vez que las dos votaciones de la investidura de este se saldaron también con un fracaso (3 de septiembre) y, tras más de un mes de espera, el rey abrió otra ronda de consultas (la quinta de la serie) los días 24 y 25 de octubre, de la que salió, de nuevo, como candidato Mariano Rajoy, cuya investidura como presidente fue finalmente votada por el Congreso de los Diputados, en el segundo intento, por mayoría simple, el 29 de octubre.

Lo primero que ha quedado bastante claro en esta serie es que el calendario de las consultas es un coto reservado a la voluntad del rey, si bien establecer en cada supuesto concreto quiénes son los líderes convocados exige —valdría decir en esto como en todo lo que ocurre en este ámbito- la colaboración y la concordia de la presidencia del Congreso, por conducto de la cual (y con su refrendo) el rey realiza, si procede, la propuesta de candidato subsiguiente a las consultas regias. Establecer la lista de los convocados es especialmente importante cuando las consultas se celebran en tracto sucesivo a la sesión constitutiva del Congreso, pues la CE es susceptible en esto de diversas lecturas. El art. 99.1 de la CE habla, en efecto, de consultas con «los representantes de los grupos con representación parlamentaria», lo cual plantea la duda de si se refiere a todas las fuerzas que hayan logrado escaños o tan solo a los representantes de aquellas que, habiéndolos logrado, lo hayan hecho con respaldo suficiente como para tener grupo parlamentario propio. En general, ha prevalecido desde siempre la primera de las interpretaciones apuntadas, de manera que las consultas, con independencia del objetivo para el que están diseñadas, también han servido para propiciar un contacto institucional del rey con todas y cada una de las formaciones políticas que han logrado representación en el Congreso. En ocasiones ello ha dado lugar a que algunas de las que teóricamente deberían ser 
llamadas rechacen de plano la posibilidad de acudir. Por ejemplo, en la secuencia de consultas que comentamos rehusaron hacerlo los representantes de Esquerra Republicana de Cataluña (nueve diputados en 2015 y en 2016) y Euskal Herria Bildu (dos diputados en 2015 y 2 diputados en 2016). Por eso, y por otras razones, con el fin de situar a la corona a resguardo de roces y situaciones comprometidas con las fuerzas políticas - como sucedería en el caso de una invitación desatendida - la ortodoxia constitucional exige que, una vez que el rey expresa el deseo de iniciar las consultas, estas tengan como presupuesto una audiencia del rey con la presidencia del Congreso; en cuyo transcurso, el rey recibe la lista de los que deben ser llamados para poder confeccionar, a la vista de esta, la convocatoria concreta de las audiencias.

Dejar a la voluntad del rey el cuándo del inicio de las consultas en cada supuesto concreto nos parece un factor de indeterminación que encaja perfectamente con su función arbitral y moderadora del funcionamiento regular de las instituciones. Ello, insistimos, sobre la base de que la voluntad del rey y la de la presidencia del Congreso tienen que concordar, pero sin perder de vista que, cuando la formación de Gobierno presenta dificultades políticas, el plazo de los dos meses que lleva directamente a la disolución de las Cámaras solo inicia cuando, habiendo ya un candidato propuesto por el rey, este se somete a la investidura de la Cámara y fracasa en la primera de las votaciones. El plazo no arranca después de la sesión constitutiva del Congreso o cuando se produce cualquiera de los supuestos que dejan vacante la presidencia del Gobierno; ni empieza a correr, insistimos, una vez que hay candidato. De ahí que no nos parezca absurdo defender márgenes de elasticidad temporal que permitan retardar razonablemente la propuesta, pues a nuestro juicio lo verdaderamente dañino, en coste político y en coste de legitimidad del sistema constitucional, es repetir elecciones en un lapso de tiempo corto, pues ello equivale, como ya hemos dicho, a levantar acta de la incapacidad de los partidos para leer la voluntad de los electores, devolviendo a estos una difusa responsabilidad de decidir sobre la situación, que resulta, a nuestro juicio, inoportuna y más bien inoperante.

A raíz de la coyuntura política española que se planteó a partir de los resultados electorales de 2015, otro factor de encendida polémica fue la renuncia de Mariano Rajoy a aceptar el encargo del rey para ser candidato tras la primera ronda de consultas (la que se celebró entre el 18 y el 22 de enero de 2015). Lo primero que se puede decir de esto es que la condición de candidato a presidente del Gobierno solo se adquiere en términos jurídico-constitucionales cuando tal condición se oficializa a través de una propuesta del rey refrendada por el presidente del Congreso y comunicada a la Cámara (y publicada en su Boletin Oficial) a los efectos oportunos. Antes de eso, solo hay las consultas y las conversaciones del rey con los representantes de los partidos. Lo segundo 
que puede decirse es bastante banal, pero quizá no esté de más recordarlo: los cargos (y los encargos) públicos son siempre y en términos absolutos renunciables, pues la figura jurídica de un candidato malgré lui o «por imperativo constitucional» no tiene encaje en el sistema. Otra cosa es que, en términos políticos, la postura de quien renuncia a ser candidato por considerar que no tiene perspectivas de éxito nos pueda parecer acertada o desacertada. En el caso concreto que comentamos, lo interesante es que de la renuncia de Rajoy a ser tenido por candidato en las circunstancias de entonces el rey dejó constancia expresa en un comunicado de la Casa de su Majestad el Rey, en la que la renuncia viene contemplada como la causa de la convocatoria inmediata de la segunda ronda de consultas, que el rey inició efectivamente cinco días más tarde y que culminó en la propuesta como candidato de Pedro Sánchez ${ }^{8}$.

Tras la celebración de la segunda de las votaciones de investidura de Pedro Sánchez, sin que este lograra el suficiente respaldo, un nuevo comunicado de la Casa de su Majestad el Rey, de fecha 7 de marzo, ya iniciada la cuenta atrás de los dos meses hacia la disolución, expresaba la voluntad del rey, comunicada al presidente del Congreso, de no celebrar "por el momento" nuevas consultas, al tiempo que exhortaba a las fuerzas políticas a «llevar a cabo las actuaciones que consideren convenientes a los efectos de lo previsto en el art. 99 de la Constitución». Y entre esa fecha y el 12 de abril, un mes y cinco días más tarde, no hubo en términos institucionales más novedad que el relevante comunicado de la Casa de su Majestad el Rey fechado ese día, en el que el rey comunicaba su intención de celebrar una nueva (la tercera) ronda de consultas y exteriorizaba lo que, a su juicio, venía a ser el objetivo de estas? .

8 El comunicado, de fecha 22 de enero, dice literalmente lo siguiente: «[... 2. En el transcurso de la última consulta celebrada con Don Mariano Rajoy Brey, Su Majestad el Rey le ha ofrecido ser candidato a la Presidencia del Gobierno. Don Mariano Rajoy Brey ha agradecido a Su Majestad el Rey dicho ofrecimiento, que ha declinado. 3. Su Majestad el Rey ha informado al Señor Presidente del Congreso de los Diputados, Don Patxi López Álvarez, de la decisión de Don Mariano Rajoy Brey. 4. Su Majestad el Rey ha convocado en audiencia al Señor Presidente del Congreso de los Diputados el próximo lunes 25 de enero, a las 17:00 horas, con el objeto de que le facilite la preceptiva lista de representantes designados por los Grupos políticos con representación parlamentaria, para llevar a cabo una nueva ronda de consultas».

9 Repárese en los términos precisos de este comunicado, que sinteriza muy bien la posición del rey, del presidente del Congreso y del propio Congreso en la formación del Gobierno: «1. S.M. el Rey, de acuerdo con lo establecido en el art. 99.4 de la Constitución, ha comunicado en el día de hoy al sr. Presidente del Congreso su decisión de celebrar nuevas consultas los días 25 y 26 de abril. 2. La finalidad de las consultas es constatar si, de la disposición que le trasladen los representantes de los grupos políticos 
Por último, tras el fracaso de Rajoy en el primero de los dos intentos de investidura a los que se sometió tras las elecciones de junio de 2016, la exhortación del rey a las fuerzas políticas, mediante un comunicado de fecha 5 de septiembre, cobró una forma mucho más enfática e incluyó una referencia a las palabras pronunciadas por el rey con ocasión del mensaje de Navidad de diciembre de $2015^{10}$.

\section{LA INTERVENCIÓN DEL CONGRESO}

Obsesionados por propiciar la estabilidad gubernamental, equiparada entonces (y no sin razón) a la estabilidad de la democracia misma, quienes

con representación parlamentaria, S.M. el Rey puede proponer un candidato a la Presidencia del Gobierno que cuente con los apoyos necesarios para que el Congreso de los Diputados, en su caso, le otorgue su confianza; o, en ausencia de una propuesta de candidato, proceder a la disolución de ambas Cámaras y a la convocatoria de nuevas elecciones generales en el momento que constitucionalmente corresponda y con el refrendo del Presidente del Congreso. 3. S.M. el Rey y el Sr. Presidente del Congreso han acordado que el día 21 de abril el Sr. Presidente hará llegar a Su Majestad el Rey la relación de los representantes designados por los grupos políticos con representación parlamentaria y ese mismo día se le comunicarán al Sr. Presidente las fechas y horas en las que serán recibidos, lo que oportunamente les será notificado por el Congreso de los Diputados el día 22 de abril. 4. En el caso de que las consultas concluyeran con una propuesta de candidato a la Presidencia del Gobierno, el Sr. Presidente del Congreso, con arreglo al Reglamento de la Cámara, procedería a convocar el Pleno del Congreso de los Diputados para el debate de investidura.5. Si las consultas concluyesen sin una propuesta de candidato, S.M. el Rey procedería, en los términos previstos en el art. 99.5 de la Constitución, a la disolución de las Cámaras y a la convocatoria de nuevas elecciones generales con el refrendo del Presidente del Congreso». En términos muy parecidos a este, se pronuncia el comunicado, de fecha, 10 de octubre de 2016, que precedió a las consultas celebradas los días 24 y 25 de octubre y, a la postre, a la sesión de investidura del candidato Mariano Rajoy que resultaría investido presidente del Gobierno; esta vez sí, en segunda votación, el día 29 de octubre.

10 "[...] A la vista de las circunstancias que de nuevo concurren, Su Majestad el Rey cree conveniente recordar su mensaje de Navidad del año pasado, en el que señaló que la pluralidad política, expresada en las urnas, conlleva una forma de ejercer la política basada en el diálogo, la concertación y el compromiso, con la finalidad de tomar las mejores decisiones que resuelvan los problemas de los ciudadanos. Y que en un régimen constitucional y democrático de Monarquía Parlamentaria como el nuestro, las Cortes Generales son la sede donde, tras el debate y el diálogo entre las fuerzas políticas, se deben abordar y decidir los asuntos esenciales de la vida nacional.» 
redactaron la CE diseñaron un parlamentarismo a la alemana con un presidente fuerte y a resguardo de operaciones parlamentarias de derribo poco meditadas. Para lograrlo optaron por un tipo de circunscripción y una fórmula de escrutinio que dificultara tener un Parlamento muy fragmentado. Pero, sobre todo, combinaron hábilmente umbrales de mayorías diversos para formar y para despedir al Gobierno. Para lo primero, una mayoría simple en segunda votación, lo que convierte la exigencia de mayoría absoluta en primera en un mero desideratum carente de efectos prácticos. Y, para lo segundo, una moción de censura con mayoría absoluta y en su variante constructiva; es decir, condicionando el éxito de la iniciativa del Congreso dirigida a terminar con el presidente al logro de un acuerdo en positivo de al menos la mitad más uno de los miembros del Congreso sobre el programa y sobre la persona llamada a sustituirlo. Entre 1978 y 2015, durante diez legislaturas de vida constitucional, el sistema parlamentario funcionó en España de manera conforme a los esquemas de quienes lo diseñaron. Incluso en defecto de mayoría absoluta, al partido vencedor de las elecciones no le resultó difícil formar Gobierno, bastándole un pacto de legislatura más o menos concreto que hiciera posible la investidura en segunda votación.

Lo que se ha revelado ahora como una tarea ardua hasta rozar lo imposible es construir con ese trasfondo, y por imperativo de las exigencias constitucionales, un acuerdo para permitir gobernar, o una "coalición ganadora» en cualquiera de sus versiones y en condiciones de romper con una tradición de gobiernos monocolor firmemente asentada. La apuesta de Rajoy por la «gran coalición» nunca encontró el más mínimo eco en el PSOE. Y la disposición de Ciudadanos, concordando sucesivamente con el candidato del PSOE y con el del PP un número de medidas para un programa, era aritméticamente insuficiente para superar el voto adverso del resto de las fuerzas políticas. En esas condiciones - y habida cuenta de la imposibilidad constatada de sumar hacia la izquierda en el caso del PSOE (con Podemos y sus fuerzas coaligadas y/o con IU), o bien hacia el nacionalismo vasco y/o catalán en el caso del PSOE, y en el del PP, tras el fracaso del primer intento de investidura, tanto en la undécima como en la duodécima legislatura - no hubo propuestas distintas a las realizadas en primer lugar. Con el reloj corriendo hacia la disolución automática por el transcurso de los dos meses, el Congreso no volvió a pronunciarse en la undécima legislatura. $\mathrm{Y}$ en la duodécima lo hizo solo in extremis, y esta vez apoyando a Rajoy después de una convulsa tormenta interna en el seno del PSOE que se llevó por medio a su secretario general, sustituido por una gestora que sacó adelante para evitar unas traumáticas terceras elecciones en el plazo de un año, el cambio de postura, desde el «no a Rajoy» sostenido sin fisuras por Pedro Sánchez, hasta la abstención que propició finalmente la 
investidura de aquel en la segunda votación de su segundo intento. Más allá de las consideraciones que podrían hacerse sobre las circunstancias que desembocaron en la dimisión del secretario general del PSOE durante la turbulenta reunión del Comité Federal del partido, celebrada unos días después de los malos resultados cosechados en las elecciones autonómicas vascas y gallegas del 25 de septiembre, lo que cabe resaltar aquí es que la literalidad del proceso pretendido por la CE se cumplió solo de manera defectuosa. En el guion del art. 99 de la CE no está escrito que haya un «derecho natural» a ser candidato del líder del partido con más escaños. Candidato puede serlo cualquiera, y lo deseable es, sin duda, que lo sea quien tenga más expectativas de éxito. Pero lo que sí quiere ese guion es que el Congreso se pronuncie sobre sucesivas propuestas cuando fracasa la primera de ellas (art. 99.4 de la CE: «Si efectuadas las citadas votaciones no se otorgase la confianza para la investidura, se tramitarán sucesivas propuestas en la forma prevista en los apartados anteriores»). Aquí no hubo propuestas sucesivas, sencillamente porque el clima político de estos meses, si algo ha confirmado, es lo que todos sabemos por activa y por pasiva: que las sedes constitucionales de la representación política hace tiempo que son sedes de una representación, pero no de la que sirve para confrontar pareceres y decantar resultados como producto de la deliberación, sino de la que actúa como un mero reflejo consecuencial de la capacidad de los partidos para tomar las decisiones que correspondan en cada momento y exigir su cumplimiento a rajatabla mediante la boca — más bien muda — de sus parlamentarios/delegados. Deplorar que las cosas sean así no tiene más sentido que el de constatar una realidad que convierte en un sinsentido la prohibición del mandato imperativo sobre la que se funda la representación de los modernos en el Estado constitucional. Pero en el camino hacia la formación de un Gobierno hubiera sido más consecuente con el diseño constitucional que, fracasada una vía, se hubieran abierto otras sobre las que el Congreso hubiera podido pronunciarse. No fue así a lo largo de estos meses de desconcierto, en los que la mano de hierro de la disciplina de partido solo se quebró paradójicamente al final del recorrido para poner de manifiesto la distancia que media entre los postulados teóricos de la representación política y la práctica del parlamentarismo en el Estado de partidos.

\section{CONCLUSIÓN: ¿EL ARTÍCULO 99 DE LA CONSTITUCIÓN ESTÁ BIEN COMO ESTÁ O CONVENDRÍA REFORMARLO?}

A la vista de las dificultades que ha planteado formar Gobierno en España, con trescientos quince días de interinidad del Gobierno cesante, con 
dos elecciones generales de por medio y el fantasma (o la pesadilla) de unas terceras rondando el horizonte político, puede sostenerse, no sin razón, que la equivocación reside en el planteamiento. Un sistema de investidura expresa previa a la asunción de las funciones de gobierno, y sujeto además a plazo perentorio, tiene, sin duda, sus riesgos; sobre todo, cuando lo que falta es el presupuesto mismo de un sistema parlamentario saneado: la disposición para pactar y la voluntad de tomar en serio el papel del Parlamento, incluso cuando acecha la tentación de utilizar la mayoría como rodillo, porque el caudal de confianza de quien gobierna permite prescindir de una y otra cosa. Para eludir tales riesgos, hay quien piensa que son preferibles formas de confianza presunta, sin investidura ex ante o intervenciones en el diseño del sistema que prescindan de la posibilidad de convocar nuevas elecciones e incidan de modo determinante sobre la actuación de las fuerzas políticas en el momento de la instauración del nexo fiduciario entre el Gobierno y el Parlamento. En el derecho positivo español, contamos, como sabemos, con la fórmula del candidato "que encabece la lista que haya obtenido mayor número de votos populares en el correspondiente Municipio» (art. $196 c$ de la LOREG cuando se trata de la elección de alcalde en defecto de mayoría absoluta constatada en una primera votación, una fórmula que sigue también, pero referida al mayor número de escaños, el Estatuto de Castilla La Mancha ${ }^{11}$. Asimismo, en un par de comunidades autónomas (Asturias y el País Vasco) el bloqueo de la investidura es sencillamente imposible al permitir candidaturas múltiples a la presidencia que obligan al parlamentario a optar entre ellas (o bien a optar entre apoyar a una de ellas o abstenerse), que se combinan con una posible repetición de votaciones parlamentarias que desembocan necesariamente en la investidura del candidato con más votos ${ }^{12}$. Son fórmulas que actúan a modo de un aviso para navegantes y muestran a todos de antemano, y sin remisión, el desenlace

11 Art. 14.5 del Estatuto: «Si las Cortes, por el voto de la mayoría absoluta de sus miembros, otorgasen su confianza al candidato, el Rey lo nombrará Presidente de la Junta de Comunidades con el título a que se refiere el apartado 1 de este artículo. De no alcanzarse dicha mayoría, se someterá la misma propuesta a nueva votación cuarenta y ocho horas después de la anterior y la confianza se entenderá otorgada si obtuviese la mayoría simple. En el supuesto de no alcanzarse esta mayoría, se tramitarán sin debate sucesivas propuestas y si en ninguna de ellas se llegara, en el plazo de dos meses, a alcanzar la mayoría simple, quedará automáticamente designado el candidato del partido que tenga mayor número de escaños».

12 Un sistema de parlamentarismo negativo que en sede de doctrina recibió hace años la atención de Francisco Bastida en su trabajo «Investidura de los presidentes autonómicos y Parlamentarismo Negativo", Revista Jurídica de Asturias, 17 (1993). 
previsible del bloqueo. Por sí solo, ello no es, sin embargo, ni un acicate ni un obstáculo para la negociación; es simplemente una manera de evitar que quien ya se pronunció en las urnas se vea de nuevo abocado a ellas por la impericia o la desidia de quienes fueron incapaces de leer el mandato de los electores y obrar en consecuencia.

Por nuestra parte, no vemos en el art. 99 de la CE la causa próxima ni remota de lo que ha ocurrido; al contrario, creemos que en él se combinan con acierto una serie de reglas que encauzan y dirigen rectamente hacia un fin la actuación de todos cuantos intervienen en la investidura. En un sistema de monarquía parlamentaria (rectius, en cualquier sistema donde el compromiso con la democracia se considera compatible con una forma de jefatura del Estado de tipo monárquico), la atribución de facultades a la persona del rey relacionadas con la formación del Gobierno (y de nuevo rectius, relacionadas, en general, con los procesos de decisión propios de la dinámica política) se ahogan en un indefectible oxímoron: se le asignan funciones excelsas bien difíciles de cumplir para cualquiera, pero que, además, solo serían de factible operatividad y rendimiento a costa de desvirtuar las exigencias de neutralidad y alejamiento que actúan como presupuesto de ellas. Por eso, los procesos de formación del Gobierno en aquellos sistemas donde todavía perdura el axioma de que el rey lo nombra y lo destituye, se rodean de una serie de ritos de objetividad (delegación de las facultades regias en una pléyade de informadores, formadores, exploradores o asesores) que actúan como parachoques en contra de la implicación monárquica $^{13}$. En un sistema como el nuestro, en el que no hay encargo para formar Gobierno, sino una pura activación de un procedimiento que está plenamente parlamentarizado (y en manos del presidente electo en lo que se refiere a la composición del Gobierno), insistimos en que el diseño admite márgenes de maniobra temporal que pueden afectar a los momentos en los que se activa la obligación de consultar o la de proponer candidato una vez realizada la ronda de consultas, pero ello siempre que (y solo cuando) la presidencia del Congreso se presente ante la opinión pública como valedora de una opción por diferir que necesariamente ha de estar relacionada con la existencia de negociaciones en curso. Aquí, como en cualquier otro ámbito de las actuaciones del rey, un desencuentro entre

13 Y en esto el sistema que nos parece más consecuente es el sueco, cuya ley de Gobierno (arts. 2 y 3), aprobada en 1974, deja en manos del presidente del Parlamento (Riksdag) la responsabilidad de reunirse con los representantes de cada grupo y formular la propuesta de candidato. La ley contempla la repetición de elecciones cuando el Pleno rechaza hasta por cuatro veces la propuesta del presidente. 
refrendante y refrendado equivaldría, lisa y llanamente, a una crisis que comprometería de una manera abierta y difícilmente superable la legitimidad del entero sistema constitucional. Otra cosa es que, una vez tramitada la propuesta y publicada en el Boletín de las Cortes, quepa retrasar a discreción la sesión de investidura. En esto creemos que, por mucha que sea la ductilidad del derecho parlamentario, el art. 170 del Reglamento del Congreso es taxativo («una vez recibida en el Congreso la propuesta de candidato a la presidencia del Gobierno el Presidente de la Cámara convocará el Pleno), por lo que no parece ese el momento propicio para intentar dilatar el dies a quo de la disolución automática.

En un terreno en el que ya hay que andar con pies de plomo para descartar ciertos supuestos como hipótesis de laboratorio, se ha planteado qué ocurriría si pasaran los meses sin que fuera posible tramitar propuesta alguna. Así como no ofrece duda el hecho de que nuestro sistema no admite disoluciones automáticas sin que alguien haya comparecido ante el Congreso como candidato y se haya sometido a la doble votación, creemos que aquí hay una laguna que convendría colmar. Una propuesta bastante razonable en este sentido es la que hace recaer sobre el presidente del Gobierno en funciones la responsabilidad de actuar como un candidato/activador del procedimiento de investidura $^{14}$. Para ello bastaría con una reforma de la Ley 50/1997, del Gobierno, cuyo art. 21.3 ya contempla, por cierto, la obligación del Gobierno en funciones de facilitar «el normal desarrollo del proceso de formación del nuevo Gobierno». Y la duda surgiría entonces en cuanto a la conveniencia de someter o no a plazo perentorio el recurso a ese remedio extremo. No creemos que fuera conveniente hacerlo; $y$, si se nos apura, se trata de una solución que solo debería activarse, a nuestro juicio, tras constatar la voluntad manifiesta de la mayor parte de las fuerzas políticas de decantarse por la celebración de elecciones. La reforma urgente de la LOREG mediante la Ley Orgánica 2/2016 para disminuir en una semana la duración del proceso electoral cuando se produce una «situación especial de nuestro sistema constitucional $»^{15}$ cual es la disolución automática del art. 99 de la $\mathrm{CE}$, es por cierto una buena prueba para rememorar la diferencia entre la ratio y la ocasio de las disposiciones legales, pero también para constatar lo sencillo que resulta moldear el ordenamiento jurídico cuando hay voluntad de hacerlo.

Si hubiera que introducir reformas en un artículo cuyo diseño, como decimos, nos parece acertado en líneas generales, creo que habría un amplio

14 Es la propuesta que ha realizado Antonio Torres del Moral (2016)

15 La expresión entrecomillada procede, como se adivina, del Preámbulo de la propia Ley Orgánica 2/2016, de 2 de noviembre. 
consenso en considerar un despropósito vincular la suerte del Congreso incapaz de generar una mayoría para la investidura a la de un Senado que no interviene en el proceso, pero cuya vida institucional queda en suspenso como consecuencia del bloqueo. Se trata de una incongruencia más de las que caracterizan la azarosa vida del Senado en nuestro sistema constitucional, pero cualquier retoque que pudiéramos sugerir en esto carecería de sentido sin plantear la razón de ser de la Cámara Alta y su necesaria reubicación para poder cumplir su cometido de Cámara de representación territorial.

Posiblemente la experiencia constitucional de una legislatura que nunca arrancó y de otra a la que le costó hacerlo varios meses sea el precio que hemos tenido que pagar para aprender a vivir en un sistema parlamentario que ha dejado atrás las certidumbres del modelo mayoritario y camina ahora por otro más proclive a la regeneración del Parlamento y a las virtudes del consenso.

Cuadro 4. Resultados de las votaciones de investidura (XI y XII Legislatura, 2016) ${ }^{16}$

\begin{tabular}{|c|c|c|c|c|}
\hline $\begin{array}{c}\text { Candidatol } \\
\text { votación/fecha }\end{array}$ & Si & Número & Abstención & Ausencias \\
\hline Pedro & 89 (PSOE) & 119 (PP) 47 (Po) & \multirow{6}{*}{$1(\mathrm{CC})$} & \\
\hline Sánchez/ & 40 (Cs) & $12(\mathrm{Ec}) 9(\mathrm{ERC})$ & & \\
\hline primera & $1(\mathrm{NC})$ & $8(\mathrm{DL}) 6(\mathrm{Em})$ & & \\
\hline votación & & $6(\mathrm{PNV}) 4(\mathrm{Co})$ & & \\
\hline $02-03-2016$ & & $2(\mathrm{IU}) 2(\mathrm{EHB})$ & & \\
\hline & & 1 (F) 1 (Idpte.) & & \\
\hline TOTAL & 130 & 219 & 1 & \\
\hline
\end{tabular}
.../...

16 Siglas de partidos. PSOE: Partido Socialista Obrero Español; PP: Partido Popular; Cs: Ciudadanos; Po: Podemos; Upo: Unidos Podemos (coalición, en junio de 2016 entre Izquierda Unida, Equo y Podemos) Ec: En Comú Podem (alianza con Podemos); ERC: Esquerra Republicana de Catalunya; DL: Democracia i Llibertat (en 2015); PDC: Partit Demòcrata de Catalunya (en 2016); Em: En Marea (alianza con Podemos); PNV: Partido Nacionalista Vasco; Co: Compromís (alianza con Podemos); IU: Izquierda Unida; UPN: Unión del Pueblo Navarro (alianza con el PP); EHB: Euskal Herria Bildu; NC: Nueva Canarias (alianza con el PSOE); CC: Coalición Canaria; F: Foro Asturias; Idpte: Independiente (corresponde a un diputado expulsado de las filas del PP por estar investigado en un caso de corrupción). 


\begin{tabular}{|c|c|c|c|c|}
\hline $\begin{array}{c}\text { Candidatol } \\
\text { votación/fecha }\end{array}$ & Si & Número & Abstención & Ausencias \\
\hline $\begin{array}{l}\text { Pedro } \\
\text { Sánchez/ } \\
\text { segunda } \\
\text { votación } \\
\text { 04-03-2016 }\end{array}$ & $\begin{array}{c}89 \text { (PSOE) } \\
40(\mathrm{Cs}) \\
1(\mathrm{NC}) \\
1(\mathrm{CC})\end{array}$ & $\begin{array}{l}119(\mathrm{PP}) 47(\mathrm{Po}) \\
12(\mathrm{Ec}) 9(\mathrm{ERC}) \\
8(\mathrm{DL}) 6(\mathrm{Em}) \\
6(\mathrm{PNV}) 4(\mathrm{Co}) \\
2(\mathrm{IU}) 2(\mathrm{EHB}) \\
1(\mathrm{~F}) 1 \text { (Indpe.) }\end{array}$ & & \\
\hline TOTAL & 131 & 219 & & \\
\hline $\begin{array}{l}\text { Mariano } \\
\text { Rajoy/ } \\
\text { primera } \\
\text { votación } \\
\text { 31-08-2016 }\end{array}$ & $\begin{array}{c}134(\mathrm{PP}) \\
32(\mathrm{Cs}) \\
2(\mathrm{UPN}) \\
1(\mathrm{CC}) \\
1(\mathrm{~F})\end{array}$ & $\begin{array}{c}84(\mathrm{PSOE}) \\
50(\mathrm{Upo}) 12(\mathrm{Ec}) \\
9(\mathrm{ERC}) 8(\mathrm{PDC}) \\
5(\mathrm{Em}) 5(\mathrm{PNV}) \\
4(\mathrm{Co}) 2(\mathrm{EHB}) \\
1(\mathrm{NC})\end{array}$ & & \\
\hline TOTAL & 170 & 180 & & \\
\hline $\begin{array}{l}\text { Mariano } \\
\text { Rajoy/ } \\
\text { segunda } \\
\text { votación } \\
02-09-2016\end{array}$ & $\begin{array}{c}134(\mathrm{PP}) \\
32(\mathrm{Cs}) \\
2(\mathrm{UPN}) \\
1(\mathrm{CC}) \\
1(\mathrm{~F})\end{array}$ & $\begin{array}{c}84(\mathrm{PSOE}) \\
50(\mathrm{Upo}) 12(\mathrm{Ec}) \\
9(\mathrm{ERC}) 8(\mathrm{PDC}) \\
5(\mathrm{Em}) 5(\mathrm{PNV}) \\
4(\mathrm{Co}) 2(\mathrm{EHB}) \\
1(\mathrm{NC})\end{array}$ & & \\
\hline TOTAL & 170 & 180 & & \\
\hline $\begin{array}{l}\text { Mariano } \\
\text { Rajoy/ } \\
\text { primera } \\
\text { votación } \\
\text { 27-10-2016 }\end{array}$ & $\begin{array}{c}134(\mathrm{PP}) \\
32(\mathrm{Cs}) \\
2(\mathrm{UPN}) \\
1(\mathrm{CC}) \\
1(\mathrm{~F})\end{array}$ & $\begin{array}{c}84(\mathrm{PSOE}) \\
50(\mathrm{Upo}) 12(\mathrm{Ec}) \\
9(\mathrm{ERC}) 8(\mathrm{PDC}) \\
5(\mathrm{Em}) 5(\mathrm{PNV}) \\
4(\mathrm{Co}) 2(\mathrm{EHB}) \\
1(\mathrm{NC})\end{array}$ & & \\
\hline TOTAL & 170 & 180 & & \\
\hline $\begin{array}{l}\text { Mariano } \\
\text { Rajoy/ } \\
\text { segunda } \\
\text { votación } \\
\text { 29-10-2016 }\end{array}$ & $\begin{array}{c}134 \mathrm{PP}) \\
32(\mathrm{Cs}) \\
2(\mathrm{UPN}) \\
1(\mathrm{~F})\end{array}$ & $\begin{array}{c}50 \text { (Upo) } \\
15(\mathrm{PSOE}) \\
12(\mathrm{EC}) 9(\mathrm{ER}) \\
8(\mathrm{PDC}) 5(\mathrm{Em}) \\
5(\mathrm{PNV}) 4(\mathrm{Co}) \\
2(\mathrm{EHB}) 1(\mathrm{NC})\end{array}$ & 68 (PSOE) & $\begin{array}{c}1 \text { (por renuncia } \\
\text { al escaño de } \\
\text { Pedro Sánchez) }\end{array}$ \\
\hline TOTAL & 170 & 111 & 68 & 1 \\
\hline
\end{tabular}

Fuente: elaboración propia. 


\section{Bibliografía}

Bagehot, W. (1974). The English Constitution. Londres: Oxford University Press.

Bastida, F. (1993). Investidura de los presidentes autonómicos y parlamentarismo negativo. Revista Jurídica de Asturias, 17, 7-37.

Belda, E. (2015). ¿Qué le falta a la Monarquía española para estar plenamente racionalizada? La Monarquía española del siglo XXI. Valladolid: Fundación Aranzadi Lex Nova.

Constant, B. (1820). Curso de Política Constitucional. Madrid: Imprenta de la Compañía.

Field, B. N. (2016). Why Minority Governments Work. Multilevel Territorial Politics in Spain. New York: Palgrave MacMillan.

García, E. (2014). El rey neutral: la plausibilidad de una lectura democrática del artículo 56.1 de la Constitución. Teoría y Realidad Constitucional, 34, 295.

González Trevijano, P. (1998). El refrendo. Madrid: CEPC.

Reniú Villamala, J. M. (2002). La formación de Gobiernos minoritarios en España (19771996). Madrid: CIS.

Revenga Sánchez, M. (1988). La formación del Gobierno en la Constitución española de 1978. Madrid: CEPC.

Torres del Moral, A. (2016). Lecciones de la pasada (no) investidura. El Mundo, 22/07/2016.

Torres Muro, I. (1995) El refrendo de la propuesta real del candidato a la Presidencia del Gobierno. Revista de Estudios Politicos, 88, 145-165. 